\title{
QUALIDADE DO LEITE EM AMOSTRAS INDIVIDUAIS E DE TANQUE DE VACAS LEITEIRAS
}

\author{
D.C. Rosa, J.M. Trentin, G.A. Pessoa, C.A.M. Silva, M.I.B. Rubin
}

Universidade Federal de Santa Maria, Departamento de Clínica de Grandes Animais, Embryolab, Prédio 97, Bloco 4, sala 428, CEP 97105-900, Santa Maria, RS, Brasil. E-mail: denizevet@hotmail.com

\author{
RESUMO
}

Amostras de leite foram coletadas de tanques de expansão $(n=69)$ e das vacas individualmente ( $n=3517)$, em propriedades com sistema de produção especializado (ES, $n=3)$, semiespecializado $(\mathrm{SE}, \mathrm{n}=5$ ) e não especializado (NE, $\mathrm{n}=7$ ). A composição, contagem de células somáticas (CCS) e teor de nitrogênio ureico (NU) foram avaliados nos diferentes sistemas e estações do ano. Os dados foram comparados aos parâmetros da Instrução Normativa 51/2002 (IN51) para a região Sul do Brasil, de maio/2009 a junho/2010. Analisando os três sistemas de produção, 42\% (n = 29/69) das amostras de leite dos tanques de expansão e $11 \%$ ( $n=375 / 3517)$ das individuais atenderam a IN51. Amostras de leite de tanque do sistema ES 70\% ( $n=14 / 20)$, SE 39\% ( $n=9 / 23)$ e NE 23\% $(n=6 / 26)$ atenderam os critérios da IN51. Amostras de leite individuais apresentaram menor percentual com parâmetros mínimos da IN51 comparada ao tanque. O leite de vacas sadias dilui a CCS de vacas doentes, indicando que a CCS do tanque não é um indicador confiável para qualidade do leite. Os teores médios de gordura, proteína e sólidos totais em amostras de tanque foram semelhantes entre os sistemas de produção. A lactose e NU nas amostras do tanque foram similares entre as estações do ano. Em contraste, a CCS do tanque e individual não alcançaram os parâmetros da IN51. O teor médio de NU foi maior $(\mathrm{P}<0,001)$ nas amostras de leite de tanque e individual do sistema especializado. A análise de amostras de leite de cada vaca permitiu melhoria nutricional do rebanho especializado.

PALAVRAS-CHAVE: CCS, tanque de expansão, composição do leite.

\section{ABSTRACT}

MILK QUALITY IN SAMPLES FROM INDIVIDUAL DAIRY COWS AND MILK TANKS. Bovine milk samples were collected from milk tanks $(n=69)$ and from individual cows $(n=3,517)$ on specialized $(S, n=3)$, partially specialized (PS, $n=5)$ and nonspecialized $(N S, n=7)$ production systems. Compositions, somatic cell count (SCC) and urea nitrogen content were analyzed for the different production systems and all the four seasons. Data were compared to the ranges allowed by the Federal Normative Instruction 51/ 2002 (IN51) for South Brazil from May 2009 to June 2010. Forty-two percent $(n=29 / 69)$ of all milk samples obtained from tanks and $11 \%$ of the individual samples in the three production systems met IN51 standards. Of the collected tank samples, 70\% $(\mathrm{n}=14 / 20), 39 \%(\mathrm{n}=9 / 23)$ and $23 \%(\mathrm{n}=6 / 26)$ of the S, PS and NS systems, respectively, met IN51 criteria. These data indicate that evaluation of individual samples yields a lower percent of conformity with IN51 standards than tank samples. This implies that the milk from healthy cows may dilute the higher SCC of diseased cows, suggesting that tank samples are not accurate for a confident milk quality indicator. The fat, protein and total solids content in the tank samples were similar among the three production systems. Average lactose and urea nitrogen content in tank samples were similar between seasons. In contrast, the average SCC was above the IN51 standard in the tank and individual samples during the fall. Urea nitrogen content average was highest $(\mathrm{P}<0.001)$ in the specialized production system, both in the tank and individual samples. The evaluation of individual samples may improve nutritional support of the specialized system.

KEY WORDS: SCC, milk tanks, milk composition.

\section{INTRODUÇÃO}

OMinistério da Agricultura, Pecuária e Abastecimento regulamenta através de instruções normativas a produção, o transporte e o processamento do leite com o objetivo de, junto com os produtores e a indústria leiteira, adotar medidas que visem ao incremento da qualidade do leite produzido no Brasil. 
O mercado internacional possui normas rígidas para garantir a qualidade do leite. Nos Estados Unidos, a regulamentação exige que a contagem de células somáticas (CCS) seja inferior a 750 mil células $\mathrm{mL}^{-1}$ (PHILPOT; NicKerson, 2002). Os países da União Europeia baseiam-se no Codex Alimentarius, que indica CCS inferior a 400 mil células $\mathrm{mL}^{-1}$.

No Brasil, segundo a IN62, os teores mínimos de gordura, proteína bruta e de sólidos desengordurados para o leite são 3,0; 2,9 e 8,4\%, respectivamente. No Rio Grande do Sul, durante a presente pesquisa, o limite máximo foi de 750 mil células $\mathrm{mL}^{-1}$, no período de julho de 2008 a dezembro de 2011. Já o teor de nitrogênio ureico (NU) que possibilita avaliar a qualidade da nutrição dos animais, e pode ser analisado na mesma amostra coletada para análise da composição e CCS, porém, não é exigido pela normativa.

Com relação à qualidade do leite, o mercado está se tornando cada vez mais exigente, graças à percepção do papel exercido pelos alimentos e seus componentes sobre a saúde do consumidor (RIBEIRO et al., 2000).

No presente estudo, os dados referentes à contagem de células somáticas, a composição do leite e ao nitrogênio ureico do leite de vacas de rebanhos das raças Jersey, Holandesa e suas cruzas foram coletados e analisados com o objetivo de verificar o percentual de amostras de tanque e individuais dos animais que atendiam aos parâmetros da IN51, assim como indicar qual o melhor sistema de produção para garantir a melhor qualidade do leite, qual a estação do ano com o maior percentual de amostras nos padrões da IN51 e se as atuais análises individuais do leite servem como padrão de controle para melhorar a sua qualidade.

\section{MATERIAL E MÉTODOS}

O presente estudo foi desenvolvido no âmbito do projeto Leite Saudável em 15 rebanhos de propriedades rurais da região central do Rio Grande do Sul, Brasil, no período de maio de 2009 a junho de 2010. O projeto foi aprovado pelo Comitê de Ética da Universidade Federal de Santa Maria sob número 48/2009.

Visitas mensais às propriedades permitiram avaliar os fatores relacionados ao manejo da ordenha, nutricional e sanitário dos rebanhos, bem como a infraestrutura das propriedades. Estas avaliações serviram de base para classificar as propriedades por sistema de produção: sistema especializado (ES, $\mathrm{n}=3$ ), semiespecializado (SE, $\mathrm{n}=5$ ) e não especializado (NE, $\mathrm{n}=7$ ), conforme GoNZALEZ et al., (2004).

No Sistema Especializado a alimentação constituía-se de dieta balanceada, ração, silagem de milho, pastagem cultivada no outono-inverno (aveia e azevém) e verão (sorgo e milheto), com oferta equilibrada de alimento durante o ano, sala de ordenha higiênica, sistema de ordenha em circuito fechado, manejo da ordenha adequado e produção deleite constante durante o ano (média 25 litros/animal/dia). No sistemaSemiespecializado, a dieta era balanceada e pastagem cultivada no outono-inverno e verão, mas a qualidade da dieta não era regular durante $o$ ano. O sistema de ordenha em circuito fechado ou balde ao pé e manejo de ordenha e produção de leite inconstante (média 20 litros/animal/dia). Animais do sistema Não Especializado não recebiam dieta balanceada, tampouco silageme pastagem cultivada, apresentavam condições nutricionais e sanitárias precárias, o sistema de ordenha com balde ao pé ou manual e o manejo de ordenha inadequado (média de produção 10 litros/animal/dia).

As coletas de amostras de leite foram realizadas em 180 visitas. Amostras individuais $(\mathrm{n}=3517)$ foram coletadas após a ordenha de cada vaca e as amostras de tanque $(n=69)$ após a ordenha de todos os animais (amostras dos tanques de expansão), totalizando 3.586 amostras. Cada amostra foi transferida diretamente do medidor para frascos de coleta com capacidade de $60 \mathrm{~mL}$ contendo uma pastilha de Bronopol ${ }^{\circledR}$ (conservante) com $8 \mathrm{mg}$ de 2-bromo-2-nitropropano-1,3-diol e 0,3 mg do agente antifúngico natamicima. As amostras homogeneizadas foram enviadas para análise de composição, contagem de células somáticas e nitrogênio ureico ao Laboratório de Fisiologia da Lactação, da Clínica do Leite, Departamento de Zootecnia da Escola Superior de Agricultura "Luiz de Queiroz" (ESALQ/ USP) de Piracicaba, São Paulo. A composição e o nitrogênio uréico foram analisados pelo método do infravermelho no equipamento Bentley 2000 (FoNSECA; SANTOS, 2000) e a contagem de células somáticas por citometria de fluxo (Somacount 300, da Bentley Instruments, Inc.).

O delineamento adotado foi o completamente casualizado (ZANELA et al., 2006), em arranjo fatorial desbalanceado. Os dados foram submetidos à estatística descritiva (médias e desvios padrões) e a análise da variância considerando os efeitos dos sistemas de produção $(\mathrm{n}=3)$, estações do ano $(\mathrm{n}$ =4), número de propriedades e animais em cada sistema. A correlação entre as variáveis foi efetuada e as médias foram analisadas pelo Teste de Comparação Múltipla de Bonferroni ao nível 0,05 de significância.

\section{RESULTADOS E DISCUSSSÃO}

O leite de qualidade deve apresentar composição química, microbiológica, organoléptica 
e número de células somáticas que atendam aos parâmetros exigidos nacionalmente (RIBEIRO et al., 2000). Devido às características de produção regional é difícil estimar o número de produtores que atendiam as metas estabelecidas pela IN51 para a qualidade do leite. Não há cadastro de levantamento de dados para a qualidade do leite na região central do RS. As indústrias possuem apenas informações de amostras de tanque de expansão referentes à composição do leite e CCS. Exames de amostras individuais das vacas nos rebanhos não são usualmente conduzidos, o que seria útil para melhor orientar os produtores para o atendimento as instruções normativas que regem as normas de qualidade do leite. O percentual das amostras de leite de tanques de expansão e as individuais das vacas deste estudo que atenderam aos padrões da IN51 foram de 42\% (n=29/69) e $11 \%(n=375 / 3.517)$, respectivamente.

O Sistema Especializado apresentou maior percentual de amostras de tanques de expansão (70,0\%, $\mathrm{n}=14 / 20$ ) atendendo aos requisitos da IN51, seguido do SE $(39,1 \%, n=9 / 23)$ e NE $(23,1 \%, n=6 / 26)$. Ao analisar as amostras individuais das vacas, este percentual foi similar nos três sistemas de produção. No sistema ES 10,5\% (249/2.364) atenderam aos requisitos da IN51, no sistema SE 11,1\% (82/738) e no sistema NE 10,6\% (44/415).

Ao avaliar os resultados relativos às estações do ano, verificou-se maior percentual de amostras de tanque de expansão no outono $(50,0 \%, 8 / 16)$, atendendo aos padrões da IN51. Nas demais estações do ano, o percentual foi 40,0\% (6/15) no inverno, $25,0 \%$ (3/12) primavera e 46,2\% (12/26) no verão. Analisadas as amostras individuais observou-se percentual inferior, sendo $14,3 \%$ (147/1.030) no outono, 14,7 (99/675) no inverno, 7,6\% (44/579) na primavera e 6,9\% (85/1.233) no verão atendendo os critérios da IN51. Esses resultados indicam que na avaliação individual encontra-se incidência menor de amostras que atendem as exigências da IN51 e que, através do leite das vacas sadias, poderá ocorrer diluição da CCS das vacas doentes, demonstrando que amostras de leite obtidas do tanque de expansão podem apresentar índices menores de CCS quando comparada a média individual.

Os resultados referentes ao efeito dos sistemas de produção e das estações do ano nas características do leite (composição, CCSeNU) encontram-se descritos nas Tabelas 1, 2, 3 e 4. Verificou-se diferença $(\mathrm{P}<$ 0,005 ) nos teores de lactose e NU (Tabelas 1 e 2) nas amostras de tanque e individuais nos três sistemas de produção. Adicionalmente, nas amostras individuais, verificou-se diferença nos teores de gordura e extrato seco desengordurado (Tabela 2), provavelmente devido à presença de animais da raça Jersey nos rebanhos. Todas estas diferenças ocorreram em parâmetros de qualidade do leite que são cada vez mais utilizados para detecção de falhas nas práticas de manejo, servindo como referência na valorização da matéria-prima (DüRR et al., 2004).

No Brasil, a produção total de leite e o teor de gordura são as características mais enfatizadas pelos serviços de controle leiteiro (FONSECA; SANTOS, 2000). Porém, a gordura é o componente de maior variabilidade no leite. Isto é evidenciado pelos altos coeficientes de variação dos teores de gordura nas amostras individuais ( $\mathrm{P}<0,001)$ ) (Tabela 3). Comercialmente, o teor de gordura no leite segue valorizado, pois já foi estabelecido que ele aumenta o rendimento industrial do leite (MAtTos; Pedroso, 2005).

Tabela 1 - Características químicas, contagem de células somáticas e níveis de nitrogênio ureico do leite nos sistemas de produção: especializado (ES), semiespecializado (SE) e não-especializado (NE)* em de amostras de tanque.

\begin{tabular}{|c|c|c|c|c|c|c|c|}
\hline Características & & ES & SE & NE & $\begin{array}{c}\text { Todos } \\
\text { sistemas } \\
\end{array}$ & $\begin{array}{l}\text { Coeficiente } \\
\text { de variação }\end{array}$ & $\mathrm{P}$ \\
\hline \multirow{2}{*}{ Gordura \% } & Média & $3,36^{a}$ & $3,08^{a}$ & $3,20^{a}$ & 3,21 & \multirow{2}{*}{$19,63 \%$} & \multirow{2}{*}{$\mathrm{P}=0,3575$} \\
\hline & Desvio Padrão & 0,45 & 0,38 & 0,88 & 0,63 & & \\
\hline \multirow{2}{*}{ Proteína \% } & Média & $3,19^{a}$ & $3,18^{a}$ & $3,10^{\mathrm{a}}$ & 3,15 & \multirow{2}{*}{$7,81 \%$} & \multirow{2}{*}{$\mathrm{P}=0,3944$} \\
\hline & Desvio Padrão & 0,14 & 0,17 & 0,35 & 0,25 & & \\
\hline \multirow{2}{*}{ Lactose \% } & Media & $4,42^{\mathrm{a}}$ & $4,43^{\mathrm{a}}$ & $4,28^{b}$ & 4,37 & \multirow{2}{*}{$3,17 \%$} & \multirow{2}{*}{$\mathrm{P}<0,0001$} \\
\hline & Desvio Padrão & 0,08 & 0,09 & 0,16 & 0,14 & & \\
\hline \multirow{2}{*}{ Sólidos totais\% } & Média & $11,90^{\mathrm{a}}$ & $11,65^{\mathrm{a}}$ & $11,56^{\mathrm{a}}$ & 11,69 & \multirow{2}{*}{$3,64 \%$} & \multirow{2}{*}{$P=0.0262$} \\
\hline & Desvio Padrão & 0,51 & 0,53 & 0,86 & 0,68 & & \\
\hline \multirow{2}{*}{ Estrato seco Desengordurado \% } & Média & $8,55^{\mathrm{b}}$ & $8,58^{\mathrm{a}}$ & $8,36^{\mathrm{b}}$ & 8,49 & \multirow{2}{*}{$5,80 \%$} & \multirow{2}{*}{$P=0,2260$} \\
\hline & Desvio Padrão & 0,17 & 0,25 & 0,40 & 0,31 & & \\
\hline \multirow{2}{*}{$\begin{array}{l}\text { Contagem de células somáticas } \\
\left(\text { mil células } \mathrm{mL}^{-1}\right)\end{array}$} & Média & $692,6^{\mathrm{a}}$ & $508,9^{a}$ & $622,3^{\mathrm{a}}$ & 604,9 & \multirow{2}{*}{$114,51 \%$} & \multirow{2}{*}{$P=0,6839$} \\
\hline & Desvio Padrão & 949,1 & 190,0 & 757,3 & 692,6 & & \\
\hline \multirow{2}{*}{ Nitrogênio Ureico (mg/dL) } & Média & $18,15^{\mathrm{a}}$ & $12,89^{\mathrm{b}}$ & $11,20^{\mathrm{b}}$ & 13,78 & \multirow{2}{*}{$39,79 \%$} & \multirow{2}{*}{$\mathrm{P}<0,0001$} \\
\hline & Desvio Padrão & 6,39 & 4,10 & 3,61 & 5,49 & & \\
\hline
\end{tabular}

*Médias na mesma linha, seguidas de letras diferentes, apresentam variação significativa através do Teste de Comparação Múltipla de Bonferroni $(\mathrm{P}<0,005)$. 
Tabela 2 - Características químicas, contagem de células somáticas e níveis de nitrogênio ureico no leite de vacas Holandesas, Jersey e cruzas nos sistemas de produção: especializado (ES), semiespecializado (SE) e não-especializado (NE)* em amostras de individuais.

\begin{tabular}{|c|c|c|c|c|c|c|c|}
\hline Características & & ES & SE & NE & $\begin{array}{c}\text { Todos } \\
\text { sistemas }\end{array}$ & $\begin{array}{l}\text { Coeficiente } \\
\text { de Variação }\end{array}$ & $\mathrm{P}$ \\
\hline \multirow{2}{*}{ Gordura \% } & Média & $3,74^{\mathrm{b}}$ & $3,49^{\mathrm{a}}$ & $3,64^{b}$ & 3,68 & \multirow{2}{*}{$27,78 \%$} & \multirow{2}{*}{$\mathrm{P}<0,001$} \\
\hline & Desvio Padrão & 0,93 & 0,97 & 1,45 & 1,02 & & \\
\hline \multirow{2}{*}{ Proteína \% } & Média & $3,26^{\mathrm{a}}$ & $3,29^{\mathrm{a}}$ & $3,26^{a}$ & 3,27 & \multirow{2}{*}{$15,09 \%$} & \multirow{2}{*}{$P=0,2260$} \\
\hline & Desvio Padrão & 0,50 & 0,46 & 0,48 & 0,49 & & \\
\hline \multirow{2}{*}{ Lactose \% } & Media & $4,35^{\mathrm{a}}$ & $4,37^{\mathrm{a}}$ & $4,25^{\mathrm{b}}$ & 4,35 & \multirow{2}{*}{$7,47 \%$} & \multirow{2}{*}{$\mathrm{P}<0,0001$} \\
\hline & Desvio Padrão & 0,30 & 0,32 & 0,41 & 0,32 & & \\
\hline \multirow{2}{*}{ Sólidos totais \% } & Média & $12,31^{\mathrm{a}}$ & $12,14^{\mathrm{b}}$ & $12,14^{\mathrm{b}}$ & 12,26 & \multirow{2}{*}{$6,29 \%$} & \multirow{2}{*}{$P=0,0008$} \\
\hline & Desvio Padrão & 1,20 & 1,28 & 1,59 & 1,27 & & \\
\hline \multirow{2}{*}{ Estratoseco desengordurado \% } & Média & $8,57^{\mathrm{b}}$ & $8,66^{\mathrm{a}}$ & $8,50^{c}$ & 8,58 & \multirow{2}{*}{$10,43 \%$} & \multirow{2}{*}{$\mathrm{P}<0,0001$} \\
\hline & Desvio Padrão & 0,53 & 0,54 & 0,56 & 0,54 & & \\
\hline \multirow{2}{*}{$\begin{array}{l}\text { Contagem de células } \\
\text { somáticas (mil células mL-1) }\end{array}$} & Média & $670,3^{a}$ & $676,0^{\mathrm{a}}$ & $818,5^{a}$ & 689,0 & \multirow{2}{*}{$109,11 \%$} & \multirow{2}{*}{$\mathrm{P}=0,1073$} \\
\hline & Desvio Padrão & 1309 & 1236 & 1585 & 1331 & & \\
\hline \multirow{2}{*}{ Nitrogênio ureico (mg/dL) } & Média & $17,66^{\mathrm{a}}$ & $12,34^{\mathrm{b}}$ & $12,91^{\mathrm{b}}$ & 15,98 & \multirow{2}{*}{$47,33 \%$} & \multirow{2}{*}{$\mathrm{P}<0,0001$} \\
\hline & Desvio Padrão & 7,94 & 5,49 & 4,79 & 7,56 & & \\
\hline
\end{tabular}

*Médias na mesma linha, seguidas de letras diferentes, apresentam variação significativa através do Teste de Comparação Múltipla de Bonferroni $(\mathrm{P}<0,005)$.

Em decorrência do melhoramento genético, os fatores nutricionais exercem influência nos componentes do leite. Segundo SuTTON (1989), a determinação da proporção de forragens na dieta dos animais determinará a adequada concentração de gordura no leite. Neste estudo, o maior percentual de gordura no leite foi detectado, inicialmente, nas amostras de tanque de expansão obtidas no outono. Com a rotina das coletas individuais confirmaramse estes dados também no inverno, pois o outono e o inverno são as estações de maior disponibilidade de forrageiras na região estudada. Nas Tabelas 3 e 4 verifica-se o incremento no teor médio de gordura no leite individual no outono e inverno. Já os teores de gordura nas amostras de tanque nos três sistemas de produção foram similares $(P=0,3575)$, o que reforça a importância da análise individual do leite para uma avaliação fidedigna.

As mudanças no teor de proteína no leite das vacas, no tanque de expansão ou individualmente, podem ocorrer ao se manipular a dieta dos animais nas distintas estações do ano. No entanto, o efeito da manipulação da dieta nos teores de proteína se mostra menos evidente que as modificações nos teores de gordura (Tabelas 3 e 4). Neste estudo, o percentual de proteína tanto das amostras de tanque, quanto nas individuais, foi similar nos três sistemas de produção (Tabelas 1 e 2). No entanto, no final do outono e início do inverno, esse teor foi superior ao das demais estações, coincidindo, justamente, com a maior oferta de forrageiras na região. Esperava-se maior teor proteico no leite de amostras de rebanhos com sistema especializado de produção devido ao melhor aporte nutricional ofertado neste sistema; esse incremento no teor de proteína, apesar de não significativo, só foi verificado nas amostras de tanque de expansão, não sendo observado nas amostras individuais. Estudos a exemplo da pesquisa de BARBOSA etal. (2012) sobre fatores que comprometem a síntese de proteína do leite continuam em desenvolvimento e o interesse da indústria pela manipulação da proteína no leite é recente.

Quanto à lactose, observa-se elevação do seu teor no leite devido ao aporte crescente de nutrientes. Os animais criados no sistema SE apresentaram maior teor de lactose nas amostras de tanque e individuais. Por outro lado, ZANELA et al. (2006) encontraram teor mais elevado no sistema ES. Neste estudo, o teor de lactose foi similar nos sistemas SE e ES (Tabelas 1 e 2). Considerando-se que a lactose está relacionada com a regulação da pressão osmótica na glândula mamária, a maior produção de lactose determina maior produção de leite (PERES, 2001). Desta forma, os sistemas com maior especialização na produção queapresentam genética superior devem apresentar, consequentemente, melhores índices de produção e de composição do leite. Os meses de inverno apresentam teores maiores de lactose $(\mathrm{P}<0,0001)$ nas amostras de tanque e individuais, o que se reflete em maior produção leite. $\mathrm{O}$ que foi aqui verificado se reflete no dia a dia nas propriedades leiteiras. Como consequência do aumento do teor de gordura no leite nas amostras de tanque e individuais, o teor de sólidos totais (Tabelas 3 e 4) foi maior no sistema especializado nos meses de outono (tanque de expansão) e inverno (individuais das vacas).

Ao se avaliar a CCS constatou-se que a média de células foi similar entre os sistemas de produção tanto nas amostras de tanque, quanto nas individuais (Tabelas 1 e 2). A CCS está relacionada com alte- 
rações nos componentes do leite, dentre os quais as proteínas apresentam a maior variação. O teor de proteína total do leite praticamente não varia com o aumento no número de células somáticas; no entanto, com esse aumento de CCS ocorre diminuição da caseína e aumento das proteínas do soro. A lactose também diminui aproximadamente $10 \%$ e o teor de gordura do leite cai proporcionalmente. (FONSECA; SANTOS, 2000).

Em 2008, Machado; Cassoli divulgaram dados sobre a CCS de rebanhos brasileiros coletados entre junho de 2007 e julho de 2008 cuja média foi de 489 mil células $\mathrm{mL}^{-1} \mathrm{e}$ o desvio padrão de $371 \mathrm{mil}$ células $\mathrm{mL}^{-1}$. No nosso estudo, a média e o desvio padrão da Contagem de Células Somáticas (CCS) dos tanques das 15 propriedades estudadas foram de $605 \pm 693$ mil células $\mathrm{mL}^{-1}$. Os valores médios das amostras individuais $(\mathrm{n}=3.517)$ foram de 689 \pm 1331 mil células $\mathrm{mL}^{-1}$. O fato da contagem de CCS no tanque ter sido menor que a média das amostras individuais se deve ao fato de que o leite das vacas com diagnóstico de mastite clínica é descartado após a ordenha dos animais, entrando no tanque o leite supostamente sem alteração. O desvio-padrão maior que a média nos alerta sobre a existência de grande variabilidade na CCS do leite em tanques e as possíveis dificuldades no manejo nutricional e na sanidade.

Tabela 3 - Características químicas, contagem de células somáticas e níveis de nitrogênio ureico de vacas Holandesas, Jersey e cruzas nas estações da primavera, verão, outono e inverno* em amostras de tanque.

\begin{tabular}{llcccc}
\hline Características & & Primavera & Verão & Outono & Inverno \\
\hline \multirow{2}{*}{ Gordura \% } & Média & $3,09^{\mathrm{ab}}$ & $3,02^{\mathrm{b}}$ & $3,58^{\mathrm{a}}$ & $3,22^{\mathrm{ab}}$ \\
& Desvio Padrão & 0,33 & 0,59 & 0,55 & 0,79 \\
\hline \multirow{2}{*}{ Proteína \% } & Média & $2,98^{\mathrm{b}}$ & $3,14^{\mathrm{b}}$ & $3,35^{\mathrm{a}}$ & $3,09^{\mathrm{b}}$ \\
& Desvio Padrão & 0,25 & 0,16 & 0,22 & 0,25 \\
\hline \multirow{2}{*}{ Lactose \% } & Média & $4,32^{\mathrm{a}}$ & $4,39^{\mathrm{a}}$ & $4,34^{\mathrm{a}}$ & $4,41^{\mathrm{a}}$ \\
& Desvio Padrão & 0,08 & 0,12 & 0,18 & 0,14 \\
\hline \multirow{2}{*}{ Sólidos Totais \% } & Média & $11,37^{\mathrm{b}}$ & $11,50^{\mathrm{b}}$ & $12,23^{\mathrm{a}}$ & $11,69^{\mathrm{ab}}$ \\
& Desvio Padrão & 0,56 & 0,53 & 0,63 & 0,73 \\
\hline \multirow{2}{*}{ Estrato seco desengordurado \% } & Média & $8,28^{\mathrm{b}}$ & $8,48^{\mathrm{b}}$ & $8,65^{\mathrm{a}}$ & $8,47^{\mathrm{ab}}$ \\
& DesvioPadrão & 0,32 & 0,20 & 0,28 & 0,39 \\
\hline Contagem de células somáticas (mil células & Média & $462,5^{\mathrm{a}}$ & $643,9^{\mathrm{a}}$ & $862,6^{\mathrm{a}}$ & $376,2^{\mathrm{a}}$ \\
mL $\left.{ }^{-1}\right)$ & Desvio Padrão & 299,6 & 835,6 & 852,7 & 285,5 \\
\hline \multirow{2}{*}{ Nitrogênio ureico mg/dL) } & Média & $14,93^{\mathrm{a}}$ & $12,88^{\mathrm{a}}$ & $14,76^{\mathrm{a}}$ & $13,37^{\mathrm{a}}$ \\
& Desvio Padrão & 4,83 & 3,97 & 6,97 & 6,57 \\
\hline
\end{tabular}

*Médias na mesma linha, seguidas de letras diferentes, apresentam variação significativa pelo teste de Teste de Comparação Múltipla de Bonferroni $(\mathrm{P}<0,005)$.

Tabela 4 - Características químicas, contagem de células somáticas e níveis de nitrogênio ureico no leite de vacas Holandesas, Jersey e cruzas nas estações da primavera, verão, outono e inverno* em amostras individuais.

\begin{tabular}{|c|c|c|c|c|c|}
\hline Características & & Primavera & Verão & Outono & Inverno \\
\hline \multirow{2}{*}{ Gordura \% } & Média & $3,64^{\mathrm{ab}}$ & $3,59^{\mathrm{b}}$ & $3,69^{b}$ & $3,85^{\mathrm{a}}$ \\
\hline & Desvio Padrão & 1,18 & 0,99 & 1,00 & 0,90 \\
\hline \multirow{2}{*}{ Proteína \% } & Média & $3,19^{\mathrm{ab}}$ & $3,17^{b}$ & $3,39^{a}$ & $3,31^{a}$ \\
\hline & Desvio Padrão & 0,48 & 0,45 & 0,47 & 0,54 \\
\hline \multirow{2}{*}{ Lactose $\%$} & Média & $4,30^{\mathrm{b}}$ & $4,34^{\mathrm{b}}$ & $4,34^{\mathrm{b}}$ & $4,39^{a}$ \\
\hline & Desvio Padrão & 0,36 & 0,31 & 0,33 & 0,26 \\
\hline \multirow{2}{*}{ Sólidos totais \% } & Média & $12,12^{\mathrm{b}}$ & $12,06^{\mathrm{b}}$ & $12,38^{\mathrm{a}}$ & $12,53^{a}$ \\
\hline & Desvio Padrão & 1,41 & 1,24 & 1,23 & 1,22 \\
\hline \multirow{2}{*}{ Estrato seco desengordurado \% } & Média & $8,48^{\mathrm{b}}$ & $8,48^{b}$ & $8,70^{\mathrm{a}}$ & $8,69^{a}$ \\
\hline & Desvio Padrão & 0,53 & 0,50 & 0,52 & 0,58 \\
\hline \multirow{2}{*}{$\begin{array}{l}\text { Contagem de células somáticas (mil células } \\
\mathrm{mL}^{-1} \text { ) }\end{array}$} & \multirow{2}{*}{$\begin{array}{l}\text { Média } \\
\text { Desvio Padrão }\end{array}$} & $697,7^{\mathrm{ab}}$ & $545,2^{\mathrm{b}}$ & $859,7^{a}$ & $683,6^{b}$ \\
\hline & & 1444 & 1144 & 1558 & 1125 \\
\hline \multirow{2}{*}{ Nitrogênio ureico (mg/dL) } & Média & $15,59^{c}$ & $14,15^{\mathrm{d}}$ & $16,83^{b}$ & $18,35^{\mathrm{a}}$ \\
\hline & Desvio Padrão & 3,54 & 6,16 & 8,66 & 9,52 \\
\hline
\end{tabular}

*Médias na mesma linha, seguidas de letras diferentes, apresentam variação significativa pelo teste de Teste de Comparação Múltipla de Bonferroni $(\mathrm{P}<0,005)$. 
Tendo-se como referência o valor máximo deCCS permitido nesta região do Brasil, que na IN51 era de 750 mil células $\mathrm{mL}^{-1}, 23 \%(16 / 69)$ das amostras de tanque e $22 \%$ (779/3.517) das amostras individuais do rebanho analisado apresentaram valores acima desse limite. Considerando 270 mil amostras avaliadas na região sudeste (MACHADO; CASSOLI, 2008), 20\% não atendiam a IN51. NormAN et al. (2009) analisando mais de 222 mil animais em todo o território norteamericano relataram que apenas $3 \%$ das matrizes de leite apresentavam CCS acima de 750 mil células $\mathrm{mL}^{-1}$. A distribuição das análises de tanque e individuais nas diferentes classes de CCS aqui verificada pode ser visualizada na Figura 1.

Considerando que desde janeiro de 2012 o limite máximo da CCS no leite do rebanho brasileiro é de 600 mil células $\mathrm{mL}^{-1}$, ainda temos um grande desafio a enfrentar. E ao consideramos padrões internacionais mais rígidos no universo de 69 amostras de tanque e 3.517 individuais aqui trabalhadas, somente $45 \%$ das amostras de tanque e $63 \%$ das individuais continham média inferior ou igual a 400 mil células $\mathrm{mL}^{-1}$.

A incidência de animais (50\%) com elevado número de células somáticas (CCS > $250 \mathrm{mil}$ células $\mathrm{mL}^{-1}$ ) indica problemas de mastite subclínica, o que dificulta a obtenção de melhores índices produtivos (Fig. 1). Nas Tabelas 5 e 6 observa-se a distribuição das amostras de leite do tanque e individuais nos diferentes sistemas de produção e nas estações do ano referentes às características descritas na IN51. No outono verificou-se o maior percentual de amostras de leite de tanque $(44 \%-7 / 16)$ e individual $(27 \%$ $281 / 1.030)$ com contagem de células somáticas $>750$ mil células $\mathrm{mL}^{-1}$. Isto se deve ao regime de chuvas desta estação do ano na região estudada e suas consequências, que conduzem ao aumento de sujidades corporais das vacas e a dificuldade de manter a limpeza das instalações. Os sistemas de produção têm influência sobre a sanidade da glândula mamária (Tabelas 5).

O manejo nutricional das propriedades poderia ser mais bem avaliado se estivesse embasado também na análise do nitrogênio uréico do leite. Este parâmetro, que caracteriza o balanço nutricional das dietas ofertadas aos animais não era exigido pela IN51 e segue sem ser exigido pela IN62, por isso, não faz parte da rotina de análise da indústria no tanque das propriedades.

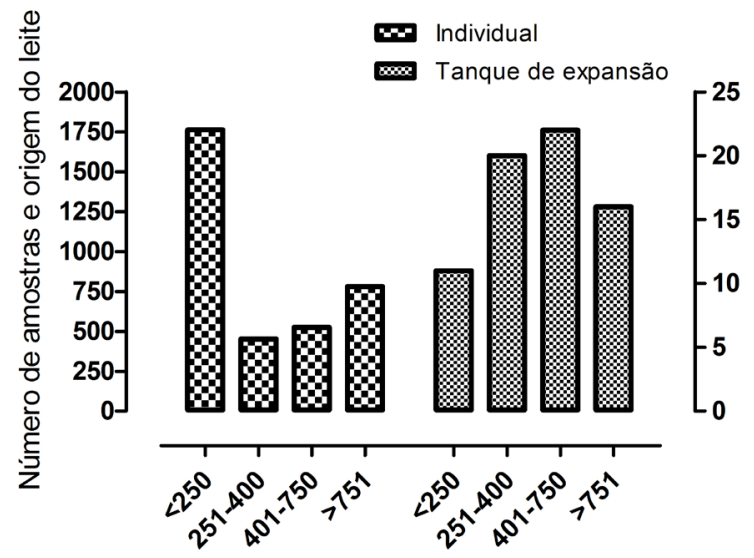

Fig. 1 - Classes de células somáticas em leite de vacas Holandesas, Jersey e cruzas (mil células $\mathrm{mL}^{-1}$ ).

Tabela 5 - Número de amostras de tanque e individuais que se enquadram nas características exigidas para qualidade de leite de vacas Holandesas, Jersey e cruzas, pela Instrução Normativa 51 do Ministério da Agricultura Pecuária e Abastecimento no período do estudo, cujo limite para Contagem de Células Somáticas na região Sul é de 750 mil células / $\mathrm{mL}$, gordura 3,0\%, proteína 2,9\% e Estrato Seco Desengordurado 8,4\% nos sistemas de produção: especializado (ES), semi-especializado (SE) e não-especializado (NE).

\begin{tabular}{|c|c|c|c|c|c|c|c|c|c|}
\hline \multirow{2}{*}{ Origem das amostras de leite } & \multirow{2}{*}{ Caracteristicas } & \multicolumn{2}{|c|}{ ES } & \multicolumn{2}{|c|}{ SE } & \multicolumn{2}{|c|}{ NE } & \multicolumn{2}{|c|}{ Total } \\
\hline & & $\mathrm{n}$ & $\%$ & $\mathrm{n}$ & $\%$ & $\mathrm{n}$ & $\%$ & $\mathrm{n}$ & $\%$ \\
\hline \multirow{8}{*}{ Tanque } & Gordura $>=3$ & 16 & $(80)$ & 16 & $(70)$ & 21 & (81) & 53 & (77) \\
\hline & Gordura $<3$ & 4 & (20) & 7 & $(30)$ & 5 & (19) & 16 & (23) \\
\hline & Proteína $>=2,9$ & 19 & (95) & 23 & $(100)$ & 17 & (65) & 59 & (86) \\
\hline & Proteína $<2,9$ & 1 & $(5)$ & 0 & $(0)$ & 9 & (35) & 10 & (14) \\
\hline & $\mathrm{ESD}>=8,4$ & 17 & (85) & 18 & (78) & 10 & (38) & 45 & (65) \\
\hline & $\mathrm{ESD}<8,4$ & 3 & (15) & 5 & $(22)$ & 16 & (62) & 24 & (35) \\
\hline & CCS $<750$ & 17 & (85) & 18 & (78) & 19 & (73) & 54 & (79) \\
\hline & CCS $>=750$ & 3 & (15) & 5 & $(22)$ & 7 & (27) & 15 & (21) \\
\hline \multirow{8}{*}{ Individuais } & Gordura $>=3$ & 308 & (74) & 512 & (69) & 1947 & $(82)$ & 2767 & (79) \\
\hline & Gordura $<3$ & 107 & (23) & 226 & $(31)$ & 417 & (18) & 750 & (21) \\
\hline & Proteína $>=2,9$ & 337 & (81) & 586 & (79) & 1850 & (78) & 2773 & (79) \\
\hline & Proteína $<2,9$ & 78 & (19) & 152 & $(21)$ & 514 & (22) & 744 & (21) \\
\hline & $\mathrm{ESD}>=8,4$ & 256 & (62) & 492 & (67) & 1498 & (63) & 2246 & (64) \\
\hline & $\mathrm{ESD}<8,4$ & 159 & (38) & 246 & (33) & 866 & (37) & 1271 & (36) \\
\hline & $\mathrm{CCS}<750$ & 316 & (76) & 566 & (77) & 1856 & (79) & 2733 & (78) \\
\hline & $\mathrm{CCS}>=750$ & 99 & (24) & 172 & (23) & 508 & (21) & 779 & (22) \\
\hline
\end{tabular}


Tabela 6 - Número de amostras de tanque e individuais que se enquadram nas características exigidas para qualidade de leite de vacas Holandesas, Jersey e cruzas, pela Instrução Normativa 51 do Ministério da Agricultura, Pecuária e Abastecimento no período do estudo, onde o limite para Contagem de Células Somáticas na região Sul é de 750 mil células/mL, gordura 3,0\%, proteína 2,9\% e Estrato Seco Desengordurado 8,4\% de acordo com as estações do ano: primavera, verão, outono e inverno.

\begin{tabular}{|c|c|c|c|c|c|c|c|c|c|}
\hline \multirow{2}{*}{ Origem das amostras de leite } & \multirow{2}{*}{ Caracteristicas } & \multicolumn{2}{|c|}{ Primavera } & \multicolumn{2}{|c|}{ Verão } & \multicolumn{2}{|c|}{ Outono } & \multicolumn{2}{|c|}{ Inverno } \\
\hline & & $\mathrm{n}$ & $((\%)$ & $\mathrm{n}$ & $(\%)$ & $\mathrm{n}$ & $(\%)$ & $\mathrm{n}$ & $(\%)$ \\
\hline \multirow{10}{*}{ Tanque } & Gordura $>=3$ & 8 & (67) & 17 & (65) & 15 & (94) & 13 & (87) \\
\hline & Gordura $<3$ & 4 & (33) & 9 & (35) & 1 & $(6)^{\prime}$ & 2 & (13) \\
\hline & $\mathrm{CCS}>=750$ & 116 & (20) & 211 & (17) & 281 & (27) & 171 & (25) \\
\hline & CCS $>=750$ & 116 & (20) & 211 & (17) & 281 & $(27)$ & 171 & (25) \\
\hline & Proteína $>=2,9$ & 10 & (83) & 24 & (92) & 16 & $(100)$ & 9 & (60) \\
\hline & Proteína<2,9 & 2 & (17) & 2 & $(8)$ & 0 & $(0)$ & 6 & (40) \\
\hline & $\mathrm{ESD}>=8,4$ & 5 & $(42)$ & 20 & (77) & 12 & (75) & 8 & (53) \\
\hline & $\mathrm{ESD}<8,4$ & 7 & (58) & 6 & (23) & 4 & (25) & 7 & (47) \\
\hline & CCS $<750$ & 10 & (83) & 21 & (81) & 9 & (56) & 13 & (87) \\
\hline & CCS $>=750$ & 2 & (17) & 5 & (19) & 7 & (44) & 2 & (13) \\
\hline \multirow{8}{*}{ Individual } & Gordura $<3$ & 448 & $(77)$ & 938 & $(76)$ & 798 & $(77)$ & 583 & (86) \\
\hline & Gordura $<3$ & 131 & (23) & 295 & (24) & 232 & (23) & 92 & (14) \\
\hline & Proteína $>=2,9$ & 420 & (73) & 897 & (73) & 903 & (88) & 553 & (82) \\
\hline & Proteína $<2,9$ & 159 & (27) & 336 & (27) & 127 & (12) & 122 & (18) \\
\hline & $\mathrm{ESD}>=8,4$ & 326 & (56) & 696 & (56) & 753 & (73) & 471 & (70) \\
\hline & $\mathrm{ESD}<8,4$ & 253 & (44) & 537 & (44) & 277 & (27) & 204 & (30) \\
\hline & CCS $<750$ & 463 & $(80)$ & 1.022 & (83) & 749 & (73) & 504 & (75) \\
\hline & $C C S>=750$ & 116 & (20) & 211 & (17) & 281 & (27) & 171 & (25) \\
\hline
\end{tabular}

O teor de nitrogênio ureico no leite tem alta correlação com o aporte proteico da dieta, bem como com a sua relação energia:proteína (OTLNER et al., 1985). Rajala-Schultz et al. (2001) afirmaram que vacas com teores médios de nitrogênio ureico no leite abaixo de $10 \mathrm{mg} / \mathrm{dL}$ têm 2,4 vezes mais chances de confirmar prenhez do que aquelas com teores acima de 15,4 mg/dL. Segundo CAmpos (2002), os teores médios ideais de NU para produção de leite de qualidade e baixas perdas reprodutivas devem estar entre 11-16 mg/dL de leite.

Ao avaliaros níveis médios denitrogênioureico do leite nas amostras de tanque e individuais constata-se que ele aumenta no leite das vacas do ES $(\mathrm{P}<0,0001)$, quandocomparadoaoSEeNE(Tabelas2e3). Segundo STUMPF JúNIOR (2000), a produção de leite representa a resposta da vaca leiteira à alimentação adequada e ao manejo racional dos recursos forrageiros disponíveis. Propriedades que mantêm dieta balanceada com volumoso, concentrado e energia permitem que os índices de nitrogênio ureico mantenham-se adequados e, consequentemente, levem ao aumento da produção de leite com maior qualidade.

MARTINS (2003) concluiu que propriedades leiteiras com queda na produção leiteira não dispõem durante todo o ano de reservas estratégicas de silagem e de adequado fornecimento de concentrado para suprir as necessidades alimentares do rebanho nos momentos em que a pastagem é restrita tanto em quantidade como na qualidade. O maior percentual de amostras de tanque com nitrogênio ureico abaixo do padrão (11 $\left.\mathrm{mg} \mathrm{dL}^{-1}\right)$, descrito como mínimo na literatura, verificou-se no sistema NE (Tabela 7), indicando a influência negativa do baixo teor de proteína na dieta, característica do Sistema NE. A análise das amostras individuais indicou incidência de maior percentual de amostras com nitrogênio ureico $(48 \%)$ no padrão $(11-16 \mathrm{mg} / \mathrm{dL})$ na primavera, enquanto que nas amostras de tanque o maior percentual (42\%) ocorreu no verão (Tabela 8 ).

Independente do sistema de produção leiteira, a alimentação inadequada ofertada às vacas é uma das principais causas dos problemas relacionados à qualidade do leite (GonZALEZ et al., 2004). Existem propriedades com condições sanitárias que possibilitam controle adequado de mastite, com baixa CCS e que atendem aos padrões da IN51, no entanto, apresentam redução no teor de sólidos totais decorrente das condições nutricionais deficientes, ou da elevação dos níveis denitrogênio ureico, conduzindo, assim, a problemas reprodutivos. As características individuais do leite e do manejo dos animais deveriam ser aproveitadas para monitorar a produção e alcançar o incremento da qualidade do leite, visto que as principais alterações aqui detectadas o foram pela análise individual do leite. A análise de amostras individuais das vacas facilita a identificação de problemas sanitários, nutricionais ou de manejo e, desta forma, a aplicação de tratamentos direcionados aos animais doentes. 
Tabela 7 - Níveis de nitrogênio ureico em amostras de leite do tanque e individual de vacas Jersey, Holandesa e cruzas criadas nos sistemas de produção especializado (ES), semiespecializado (SE) e não-especializado (NE).

\begin{tabular}{|c|c|c|c|c|c|c|c|c|c|c|c|c|}
\hline \multirow{3}{*}{$\begin{array}{l}\text { Parâmetros mg } \\
\mathrm{dL}^{-1}\end{array}$} & \multicolumn{6}{|c|}{ Sistemas de produção tanque } & \multicolumn{6}{|c|}{ Sistemas de produção individual } \\
\hline & \multicolumn{2}{|c|}{ ES } & \multicolumn{2}{|c|}{ SE } & \multicolumn{2}{|c|}{ NE } & \multicolumn{2}{|c|}{ ES } & \multicolumn{2}{|c|}{ SE } & \multicolumn{2}{|c|}{ NE } \\
\hline & $\mathrm{n}$ & $\%$ & $\mathrm{n}$ & $\%$ & $\mathrm{n}$ & $\%$ & $\mathrm{n}$ & $\%$ & $\mathrm{n}$ & $\%$ & $\mathrm{n}$ & $\%$ \\
\hline de 11 a 16 & 7 & 35 & 8 & 35 & 10 & 38 & 840 & 36 & 265 & 36 & 154 & 37 \\
\hline$<11$ & 1 & 5 & 10 & 43 & 13 & 50 & 394 & 17 & 315 & 43 & 159 & 38 \\
\hline$>16$ & 12 & 60 & 5 & 22 & 3 & 12 & 1.130 & 48 & 158 & 21 & 102 & 25 \\
\hline Total & 20 & 100 & 23 & 100 & 26 & 100 & 2.364 & 100 & 738 & 100 & 415 & 100 \\
\hline
\end{tabular}

Tabela 8 - Níveis de nitrogênio uréico no tanque e amostras individuais de leite bovino obtidas em distintas estações climáticas durante 12 meses.

\begin{tabular}{|c|c|c|c|c|c|c|c|c|}
\hline \multirow{3}{*}{$\begin{array}{l}\text { Origem das amostras de leite } \\
\mathrm{mg} \mathrm{dL}^{-1}\end{array}$} & \multicolumn{8}{|c|}{ Estação } \\
\hline & \multicolumn{2}{|c|}{ Primavera } & \multicolumn{2}{|c|}{ Verão } & \multicolumn{2}{|c|}{ Outono } & \multicolumn{2}{|c|}{ Inverno } \\
\hline & $\mathrm{n}$ & $\%$ & $\mathrm{n}$ & $\%$ & $\mathrm{n}$ & $\%$ & $\mathrm{n}$ & $\%$ \\
\hline \multicolumn{9}{|l|}{ Tanque } \\
\hline de 11 a 16 & 4 & 33 & 11 & 42 & 6 & 38 & 4 & 27 \\
\hline$<11$ & 2 & 17 & 10 & 38 & 5 & 31 & 7 & 47 \\
\hline \multirow[t]{2}{*}{$>16$} & 6 & 50 & 5 & 19 & 5 & 31 & 4 & 27 \\
\hline & 12 & 100 & 26 & 100 & 16 & 100 & 15 & 100 \\
\hline \multicolumn{9}{|l|}{ Individuais } \\
\hline de 11 a 16 & 276 & 48 & 418 & 34 & 388 & 38 & 177 & 26 \\
\hline$<11$ & 52 & 9 & 399 & 32 & 262 & 25 & 155 & 23 \\
\hline \multirow[t]{2}{*}{$>16$} & 251 & 43 & 416 & 34 & 380 & 37 & 343 & 51 \\
\hline & 579 & 100 & 1233 & 100 & 1030 & 100 & 675 & 100 \\
\hline
\end{tabular}

\section{CONCLUSÕES}

Nenhum dos sistemas de produção leiteira estudados serve como modelo ideal para o incremento da composição e da qualidade do leite. No período de outono e início do inverno ocorre percentual maior de amostras de leite atendendo aos critérios mínimos exigidos pela IN51, devidoao melhor aporte nutricional nesta época. Neste período a CCS sobe, tanto nas amostras individuais como de tanque, indicando falha de manejo, provavelmente devido ao regime característico de chuvas desta época do ano na região estudada, o que leva ao aumento da contaminação do ambiente e, consequentemente, ao aumento de casos de mastites subclínicas.

As análises individuais doleiteretratam fielmente o manejo sanitário e nutricional empregado nas propriedades nos diferentes sistemas de produção e estações do ano, devendo servir de orientação para melhorar a qualidade do leite; essa análise permite identificar no rebanho quais os animais que prejudicam a qualidade do leite e tratá-los da forma adequada.

\section{REFERÊNCIAS}

BRASIL. Ministério da Agricultura, Pecuária e Abastecimento. Departamento de Inspeção de Produtos de Origem Animal. Instrução normativa no ${ }^{\circ}$ 51, de 18 de setembro de 2002. Publicado no Diário Oficial da União de 20/09/2002, Seção 1, Página 13. Aprova os regulamentos técnicos de produção, identidade e qualidade do leite tipo A, do leite tipo B, do leite tipo C, do leite pasteurizado e do leite Cru refrigerado e o regulamento técnico da coleta de leite cru refrigerado e seu transporte a granel.

BARBOSA R.S. Caracterização eletroforética de proteínas e estabilidade do leite em vacas submetidas à restrição alimentar. Pesquisa Agropecuária Brasileira, v.47, n.4, p.621-628, 2012.

CAMPOS, R. Alguns indicadores metabólicos no leite para avaliar a relação nutrição: fertilidade. In: CONGRESSO BRASILEIRO DE MEDICINA VETERINÁRIA, 29., 2002, Gramado, RS. Anais. Gramado, 2002. p.40-48.

CASSOLI, L.D.; MACHADO, P.F. Diagnóstico da qualidade do leite na região sudeste entre 2005 e 2008. In: CONGRESSO BRASILEIRO DE QUALIDADE DO LEITE, 3., 2008, Recife. Anais. Recife: CCS Grafica Editora, 2008. v.1. p.45-51.

DÜRR, J.W.; CARVALHO, M.P.; SANTOS, M.V. Programa nacional de melhoria da qualidade do leite: uma oportunidade única. In: ___. (Ed.). O compromisso com a qualidade do leite no Brasil. Passo Fundo: Editora Universidade de Passo Fundo, 2004. 331p. p.38-55.

FONSECA, L.F.L da; SANTOS, M.V. dos Qualidade do leite e controle da mastite. São Paulo: Lemos Editorial, 2000. 175p. 
GONZALEZ, H.L.; FISCHER, V.; RIBEIRO, M.E.R.; GOMES, J.F.; STUMPF JÚNIOR, W.; SILVA, M.A. da Avaliação da qualidade do leite na bacia leiteira de Pelotas, RS. Efeito dos meses do ano. Revista Brasileira de Zootecnia, v.33, n.6, p.1531-1543, 2004.

MACHADO, P.F.; CASSOLI, L.D. Diagnóstico da qualidade do leite na região sudeste. In: MESQUITA, A.J.; DÜRR, J.W.; COELHO, K.O. (Ed.). Perspectivas e avanços da qualidade do leite no Brasil. Goiânia: Talento, 2006. 352p.

MARTINS, P.R.G. Avaliação da qualidade do leite em diferentes sistemas de produção e meses do ano. 2003. 61p. Dissertação (Mestrado em Produção Animal) - Universidade Federal de Pelotas, Pelotas, 2003.

MATTOS, R.S.W.; PEDROSO, M.A. Influência da nutrição sobre a composição de sólidos totais no leite. In: SIMPÓSIO SOBRE BOVINOCULTURA DE LEITE, 5., 2005, Piracicaba, SP. Anais. Piracicaba, 2005. p.103-128. NORMAN, H.D.; MILLER R.H.; ROSS JUNIOR, F.A. Somatic cell counts of milk from Dairy Herd Improvement herds during 2008. In: (Ed.). Animal Improvement Programs Laboratory. Beltsville: ARSUSDA, 2009.

OLTNER, R.; EMANUELSON, M.; WIKTORSSON, H. Urea concentrations in milk in relation to milk yield, live weight, lactation, number and amount and composition of feed given to dairy cows. Livestock Production Science, v.12, p.47-57, 1985.

PERES, J.R. O leite como ferramenta do monitoramento nutricional. In: (Ed.). FÉLIX, H.D. Uso do leite para monitorar a nutrição e o metabolismo de vacas leiteiras. Porto Alegre: Gráfica da UFRGS, 2001. p.30-45.

PHILPOT, W.N.; NICKERSON, S.C. Vencendo a luta contra a mastite. São Paulo: Editora Milkbizz, 2002. 30p.

RAJALA-SCHULTZ, P.J., SAVILLE W.J.A., FRAZER G.S., WITTUM T.E. association between milk urea nitrogen and fertility in ohio dairy cows. Journal of Dairy Science, v.84, p.482-489, 2001.

RIBEIRO, M.E.R.; STUMPF JÚNIOR, W.; BUSS, H. Qualidade de leite. In: BITENCOURT, D.; PEGORARO, L.M.C.; GOMES, J.F. (Ed.). Sistemas de pecuária de leite: uma visão na região de clima temperado. Pelotas: Embrapa Clima Temperado, 2000. p.175-195.

STUMPF JÚNIOR, W. Produção de leite no Rio Grande do Sul: produtividade e competitividade frente ao Mercosul. In: CICLO DE PALESTRA EM PRODUÇÃO DE BOVINOS, 5., 2000, Canoas, RS. Anais. Canoas, 2000. p.19-30.

SUTTON, J.D. Altering milk composition by feeding. Journal of Dairy Science, v.72, p.2801-2814, 1989.

ZANELA M.B.; FISCHER, V.; RIBEIRO, M.E.R.; STUMPF JÚNIOR, W.; ZANELA, C,; MARQUES, L.T.; MARTINS, P.R.G. Qualidade do leite em sistemas de produção na região sul do Rio Grande do Sul. Pesquisa Agropecuária Brasileira, v.41, n.1, p.153-159, 2006.

Recebido em 18/7/11

Aceito em 22/10/12 